\title{
WASTE MANAGEMENT ASSESSMENT OF CANDIDATE MATERIALS FOR HIPER REACTION CHAMBER
}

\author{
J. Sanz ${ }^{1,2}$, R. Juárez ${ }^{2}$, F. Ognissanto 2 J.M. Perlado ${ }^{2}$ \\ 1Dept. ingeniería energetica (UNED), Juan del Rosal 12, Madrid, Spain, 28040 \\ 2 Insituto de Fusión Nuclear/UPM, José Gutiérrez Abascal 2, Madrid, Spain, 28006, rafael.juarez@upm.es
}

One of the critical decisions in the HiPER project is to select the most appropriate material for the reaction chamber. Within this framework, we investigate the performance of different steel alloys with respect to waste management. The capabilities of commercial steels, both austenitic and ferritic/martensitic, compared to reducedactivation ferritic/martensitic steels are evaluated as for different waste management strategies (near surface burial, clearance, hands-on and remote recycling). The examined materials are: SS304, SS316, mod.9Cr-1Mo and HT9 and EUROFER. Real impurities concentrations are taken into account, and their impact is analyzed. In the study, we have assumed the most exigent HiPER $4 a$ irradiation scenario. Commercial steels revealed to be a suitable choice for the HiPER reaction chamber, as far as their waste management options do not differ significantly from those of the reduced activation ferritic steel case. We found that for mod.9Cr-1Mo and EUROFER hands-on recycling is already possible after a cooling time shorter than 50 years and that shallow-land burial is practicable for all the steel alloys studied. The impurities present in the real heats affects the cooling time for manual recycling but not significantly. Shallow-land burial feasibility is not perturbed by the presence of impurities in the real commercial heats. Moreover, the impact of activation cross section uncertainties on the waste management assessment of the irradiated steels has been analyzed, and it is found to be of no practical significance to determine eligibility of the considered steels for the HIPER 4 a reaction chamber.

\section{INTRODUCTION}

One of the issues in the HiPER project is to select the material for the reaction chamber. The HiPER 4a reaction chamber will deal with a neutron yield environment that could reach up to $1.2 \cdot 10^{5} \mathrm{MJ} / \mathrm{yr}$. This represents two orders of magnitude higher compared to $\mathrm{NIF}^{1}$, the inertial fusion experimental facility that could be considered most similar to HiPER 4a. This difference strongly questions the performance of a NIF-like reaction chamber under the HiPER 4a irradiation environment. In addition to higher temperatures and levels of radiation damage in the HiPER chamber materials, the resulting neutron induced radioactivity would be significantly higher if the same material than in NIF were used.

In NIF, an aluminum alloy is used as chamber structural material, but here for HIPER 4a, we have decided to start studying the possibility of using steels for the reaction chamber because of their better thermomechanical properties. Steels, which are widely used in power plants and other industries under demanding operational requirements, have been considered from the beginnings of fusion technology as one of the most promising candidate structural materials for inertial and magnetic fusion energy (IFE and MFE) reactor chambers. $^{2-13}$ As continuation of the ARIES-IFE study ${ }^{12}$, an extensive activation analysis in selecting steels for the HYLIFE-II chamber qualifying for successful waste management was performed ${ }^{13}$. Different commercial austenitic and Cr-Mo ferritic/martensitic steels, as well as some MFE-intended reduced-activation steels were studied. Real compositions, including existing and technologically achievable chemical content of impurities, were considered. The impact of activation cross-section uncertainties on the waste management assessment was investigated, exploring their effect on the identification of the critical alloying and impurity elements as well as in the eligibility of the steels.

In this paper a similar study is intended to be done but using the irradiation scenario of the HiPER $4 \mathrm{a}$ reaction chamber and in addition an updated approach regarding waste management strategies in fusion has been followed $^{14}$. The possibility of selecting commercial steels rather than reduced activation ferritic steels as an acceptable option with respect to waste management is one of the important issues addressed in the study. 


\section{PROBLEM DESCRIPTION AND COMPUTATIONAL METHODOLOGY}

\section{II.A. Candidate materials: Commercial and Reduced Activation Ferritic Steels}

We assess the waste management options of both commercial and reduced activation steels. Here we will indicate the steels considered and references where compositions for alloying and impurity elements can be found.

As for commercial austenitic steels, we have taken: i) SS 304, nominal $18 \mathrm{Cr}-10 \mathrm{Ni}-2 \mathrm{Mn}-0.08 \mathrm{C}$, which was proposed for HYLIFE-II $\mathrm{I}^{3,4}$, and ii) a specific SS316 selected as structural material in the ITER project, nominal $18 \mathrm{Cr}-12 \mathrm{Ni}-2 \mathrm{Mn}-2 \mathrm{Mo}-0.02 \mathrm{C}^{5,6}$.

Regarding commercial ferritic/martensitic steels, we investigate the activation of HT9 and mod.9Cr-1Mo (T91), steels considered for different nuclear -fusion and fast reactors- applications ${ }^{7,}{ }^{8}$. Sandvik HT9, nominal $12 \mathrm{Cr}-1 \mathrm{Mo}-0.3 \mathrm{~V}-0.5 \mathrm{~W}-0.5 \mathrm{Ni}-0.2 \mathrm{C}$ was used for the IFE LIBRA reactor concept. ${ }^{2}$ The composition of T91 ferritic steel, nominal $9 \mathrm{Cr}-1 \mathrm{Mo}-0.2 \mathrm{~V}-0.07 \mathrm{Nb}-0.06 \mathrm{~N}-0.1 \mathrm{C}$, is taken from Ref. 7.

Concerning reduced activation ferritic steels, the MFE DEMO reactors studies PPCS ${ }^{9}$ and ARIES-CS ${ }^{10}$ recommend EUROFER and F82H, respectively. Given the similar composition of these steels, here only one option is investigated, that of EUROFER ${ }^{11}$.

\section{II.B. Computational Tools}

We compute the neutron flux with $\mathrm{MCNPX}^{15}$ in a Vitamin-J structure to be used as input for the inventory/activation calculations. We have assumed a $10 \mathrm{~cm}$ thick spherical shell for the chamber, followed by a $40 \mathrm{~cm}$ thick borated concrete shell shield. The spectrum of neutrons escaping the DT capsule is taken from ${ }^{16}$, corresponding to shock ignition detonation scheme. The neutron spectrum is a very peaked distribution at 14.1 $\mathrm{MeV}$, and presents very little differences regarding with other thermonuclear neutron spectrum. The main differences this ignition scheme are related to $\mathrm{X}$-rays and ions spectrums.

The radionuclide inventory, the quantities necessaries for the waste management assessment and the estimated uncertainties for all them have been computed with the ACAB activation code. ${ }^{17}$ Calculations have been performed with nuclear data from the libraries EAF-2007 and EAF- $2010^{18}$, and the results obtained are found to the same for these HiPER applications.

The procedure for propagation of activation cross section uncertainties to radionuclide inventory and associated response functions uses a Monte Carlo method based on a simultaneous random sampling of all the cross section probability density functions (PDF). ${ }^{19}$ This methodology allows dealing with the global effect of the complete set of cross section uncertainties. The PDF for each cross section is assumed to be lo lognormal, i.e., for any cross section $\sigma$, we can define the random variable $\log \left(\sigma / \sigma_{0}\right)$, where $\sigma_{0}$ is the best-estimate cross section value contained in the standard EAF file, that follows a normal distribution $\mathrm{N}(0, \Delta)$, with $\Delta=\Delta_{\mathrm{EAF}} / 3$, being $\Delta^{2}{ }_{\mathrm{EAF}}$ the variance values included in the EAF_UN uncertainty file. ${ }^{20}$ These EAF_UN uncertainties values are defined as three times the experimental standard deviation of $\sigma$, i.e, $\Delta_{\text {EAF }}=3 \Delta_{\text {EXPERIMENTAL }}$, in order to represent a $99.7 \%$ confidence level. The results presented in this paper (see section III.D) have been obtained with a 1000 histories sample size, which is found appropriate for these applications.

\section{II.C. Waste Management Assessment}

In the HiPER project phase $4 \mathrm{a}$, the most exigent irradiation scenario suggested up to now is characterized by $100 \mathrm{MJ}$ neutron yields shots, with 100 shots in a single burst at $10 \mathrm{~Hz}$ (see Fig. 1). One burst will take place every month. The assumed lifetime for the facility is 20 years, what represents a total of 240 bursts.

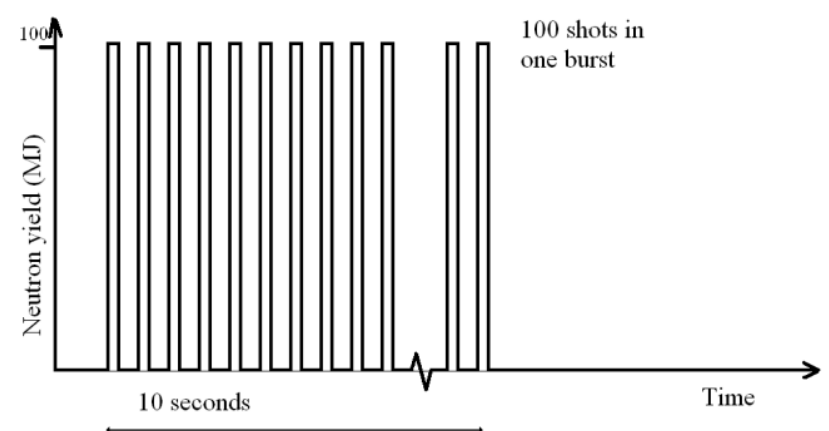

Fig. 1. Time description of one burst. It is composed by 100 shots of $100 \mathrm{MJ}$, taking place at $10 \mathrm{~Hz}$. After one month of cooling time, next burst starts.

To assess the waste management, we have computed the following quantities: Contact Dose Rate, Waste Disposal Rating ${ }^{21}$, and Clearance index ${ }^{22}$.

The Contact Dose Rate is the quantity which indicates the type of handling necessary to manipulate the material. The dose rate limit of $10 \mu \mathrm{Sv} / \mathrm{h}$ (Ref. 23) is set for Hands-on Recycling (HoR). The Waste Disposal Rating, a US index, indicates if the activated component will qualify as Class $\mathrm{C}$ shallow-land burial waste $(\mathrm{WDR}<1)$, while the Clearance index $(\mathrm{CL}<1)$ stands for an unconditional exemption of radiological controls for the waste. As it is still difficult to put into practice a Clearance, the waste management strategy is to reach the HoR limit as soon as possible, in order to recycle the material more easily. If the required time for recycling is 
too long, we explore the US index to figure out a possible solution or burying it in a shallow-land burial.

\section{RESULTS AND ANALYSIS}

\section{III.A. Waste Management Assessment of steels}

We have analyzed the steels SS304, SS316, HT9, T91, and EUROFER97. The study has been performed considering real heats with measured impurities concentrations. In table I a summary of the waste management assessment of the steels is presented. For each different class one single steel alloy has been selected as representative: the SS316 for austenitic commercial steels, HT9 for ferritic/martensitic commercial steels and EUROFER97 for reduced activation ferritic steel. We have also included T91 to remark its behaviour.

TABLE I. Summary of waste management assessment for different steels

\begin{tabular}{|c|c|c|c|}
\hline Steel & $\begin{array}{c}\text { Years to } \\
\text { HoR limit }\end{array}$ & WDR $<1$ & $\begin{array}{c}\text { Clearance } \\
(500 \text { years })\end{array}$ \\
\hline $\begin{array}{c}\text { SS316LN } \\
\text { ITER grade }\end{array}$ & $65-70$ & $7.53 \cdot 10^{-3}$ & No \\
\hline HT9 & $55-60$ & $3.39 \cdot 10^{-3}$ & No \\
\hline T91 & $40-45$ & $7.28 \cdot 10^{-3}$ & No \\
\hline EUROFER97 & $40-45$ & $5.31 \cdot 10^{-5}$ & No \\
\hline
\end{tabular}

The WDR are all well below the unit limit, so that all the steels here considered can be qualified as shallow-land burial class $\mathrm{C}$ wastes. In table I we find also the cooling times necessary to reach HoR and if Clearance is allowed after 500 years. This time limit has been chosen to point out that this strategy is not suitable for any alloy, so that the most reasonable approach is to select the material that needs the shortest time to get the HoR limit.

\section{III.B. Nickel and Cobalt as critical elements}

From the study of the waste management assessment we come to two conclusions about the Hands-on Recycling: Nickel and Cobalt are identified as critical elements, while the traditionally undesired Molybdenum and Niobium elements for reduced-activation steels are not troublesome in the HiPER 4a scenario.

When the contact dose rate meets the HoR limit, the main contributors to the dose are ${ }^{54} \mathrm{Mn}$ and ${ }^{60} \mathrm{Co}:{ }^{54} \mathrm{Mn}$ derives mainly from the iron present in the steel alloy, so its contribution cannot be diminished, the ${ }^{60} \mathrm{Co}$ derives from Nickel and Cobalt, where the first one is an intended element for the steels SS304 and SS316 and for HT9while the second one is an impurity in the studied steels.

The presence of Cobalt is intrinsically bounded with that of the Nickel ${ }^{10}$, so if we reduce the last one we could also have less Cobalt reducing problems derived from both the Ni and the Co impurity.

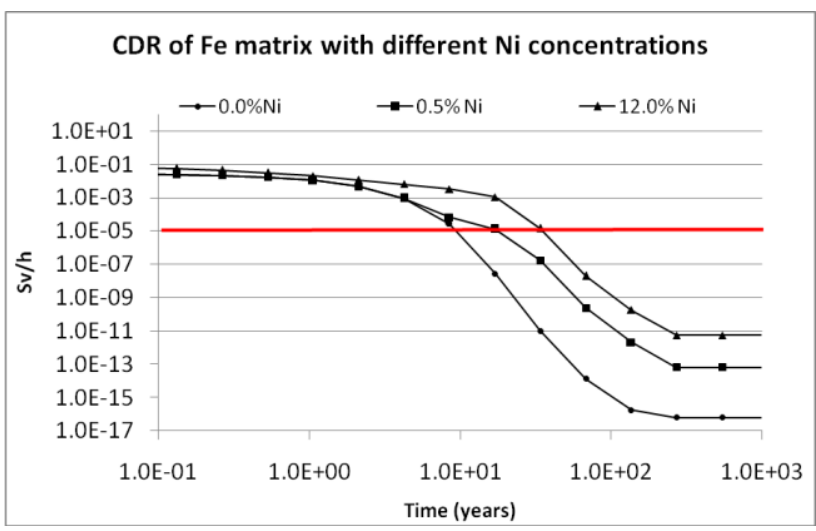

Fig. 2. Time evolution of Contact Dose Rate of a pure Iron matrix with different concentrations of Nickel.

To show the influence of Nickel, we have computed the contact dose rate time evolution for a pure iron matrix with a content of $12.0 \mathrm{w} \%, 0.5 \mathrm{w} \%$ and $0.0 \mathrm{w} \%$ of Nickel, representing austenitic, ferritic, and reduced activation ferritic steels or T91, respectively. As it is shown in Fig. 2 , the cooling times to reach the HoR limit are 35, 18 and 8 years respectively. We can conclude that depending on the real heat considered the time HoR limits can vary between about 40 and 70 years, and if we remove the Nickel content we go down to 10 years. An analogous study has carried out with Cobalt and presented in the paragraph III-D.

In the HiPER 4a irradiation scenario, it seems to be a reasonable objective reaching the HoR limit in 25 years of cooling time. We have calculated the maximum allowed Nickel and Cobalt concentrations in order to satisfy this condition. Assuming a pure iron matrix of steel density mixed with the elements under exam, we obtain $0.6 \mathrm{w} \%$ of Nickel or 6wppm of Cobalt.

Considering the lowest nominal Nickel concentration the best candidates are T91 and EUROFER97 since they have $0 \mathrm{w} \%$ nominal $\mathrm{Ni}$. The Cobalt concentration is mainly a matter of impurities control.

\section{III.C. Molybdenum and Niobium requirements}

In the reduced-activation steels for magnetic DEMO, Molybdenum and Niobium play a very important role in the impurities control. In the HiPER 4a scenario, however, they are not troublesome.

In Fig. 3 we show the time evolution of the contact dose rate of EUROFER and T91. We observe two main differences. Before reaching the HoR limit, the ${ }^{187} \mathrm{~W}$ 
derived from the $\mathrm{W}$ contained in the EUROFER97 generates higher contact dose rates than in the case of T91. After crossing the HoR limit, the content of Niobium in the T91 is responsible for a contact dose rate two orders of magnitude higher than in the case of EUROFER97: we note that anyway, having already crossed the HoR limit, this fact does not affect the conclusions in the comparison of the two materials. As both steels present similar concentrations of Cobalt and Nickel, they both reach the HoR at the same time.

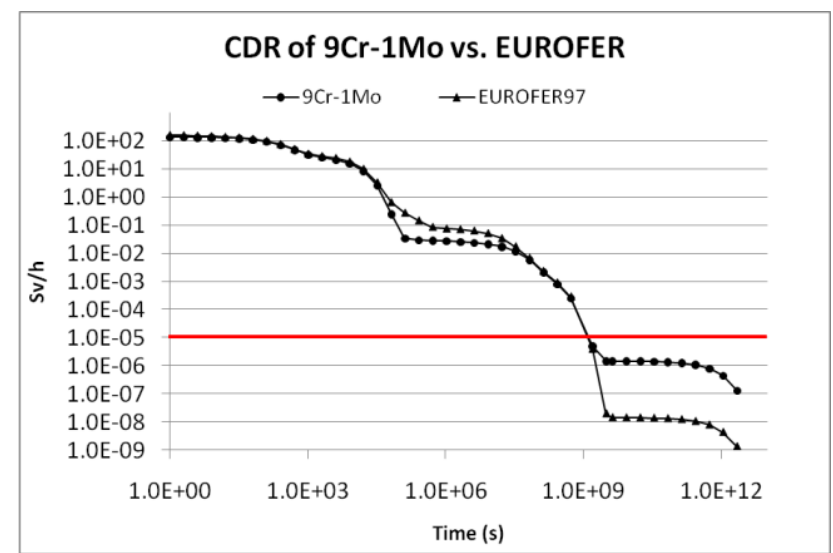

Fig. 3. Comparison of Contact Dose Rate of T91 and EUROFER97

It can be seen in table I that the WDR is very low for both: still with an increase of three orders of magnitude in Molybdenum and Niobium concentrations we have $\mathrm{WDR}=1$. Therefore from the WDR point of view using a reduced activation ferritic steel is unnecessary.

The restrictions on the Molybdenum and Niobium contents traditionally adopted in the magnetic fusion community become more relaxed. The upper limit concentrations of Molybdenum and Niobium for having 25 cooling years at most to reach the HoR have been calculated for the HiPER 4a scenario, following the same method adopted for Cobalt and Nickel. The pure iron matrix shows no restriction in Molybdenum content in contrasts with the EUROFER requirements for MFE, and Niobium is limited to $0.4 \mathrm{w} \%$ that is a much higher concentration than the $10 \mathrm{wppm}$ limitation for the EUROFER $^{11}$. It must be noticed that although Niobium is limited regarding with Hands-on Recycling, the current concentrations in T91 are enough to guarantee a reasonable waste management assessment.

From the contact dose rates standpoint we conclude that in the scenario considered the commercial steel T91 behaves slightly better than EUROFER97. In relation to WDR both steels may be easily stored in Shallow-land burials.

\section{III.D. Waste Management Assessment of T91}

The T91, among the analyzed steels, reveals to be the best choice regarding to waste management assessment.

We studied the effect of Cobalt as impurity in this material repeating the calculations assuming a concentration of $0 \mathrm{w} \%$ of Cobalt in the real heat. We show in Fig. 4 the result for the contact dose rate, together with the case of the intended T91 and with hypothetical $0 \mathrm{w} \%$ of Nickel and Cobalt contents.

It can be observed that the absence of Cobalt would reduce the cooling time for the HoR from 45 years to 20 years and if both Nickel and Cobalt were absent the cooling time would be further reduced at around 10 years.

The WDR for the real heat is well below the unit, $\sim 10^{-3}$, therefore a Shallow-land burial is allowable. Clearance is not possible before 500 years in any case, so it is abandoned as target for the reaction chamber waste management assessment.

For what concerns the uncertainties analysis we have calculated the probability distribution for the contact dose $D$ together with the relative errors $E=\left(D-D_{0}\right) / D_{0}$, where $D_{0}$ is the dose rate calculated without uncertainties. Then we computed the relative error at $95 \%$ of confidence, that is the value E95, for which the relative error is equal or smaller with a probability of $95 \%$ (i.e., $\mathrm{P}(\mathrm{E} \leq \mathrm{E} 95)=95 \%$ ).

The results are resumed in Fig. 5. We can identify three regions: from about 3 hours after the shutdown till about one year the E95 is $<10 \%$, then it increases till a maximum that correspondents to $37 \%$ at 16 years, finally it assumes a constant value of about $35 \%$.

For each of these regions there is one isotope whose production essentially contributes to the uncertainty and they also result to be the dominant contributors to the contact dose in the respective regions. These radionuclides are: ${ }^{54} \mathrm{Mn}$ at lowest cooling time, ${ }^{60} \mathrm{Co}$ and then ${ }^{94} \mathrm{Nb}$. In the plot their correspondent half-life and contributions to the total dose at the half-life time (in \%) are indicated.

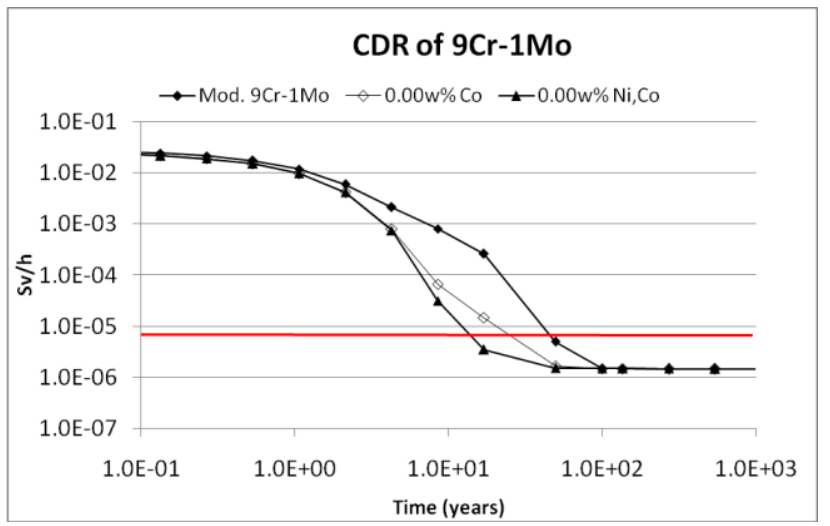

Fig. 4. Time evolution of Contact Dose Rate for T91, T91 with no Cobalt, and T91 without Cobalt and Nickel. 
From these results we obtain that the uncertainties introduced by the activation cross-sections do not change the final preference for the T91 among the studied steel.

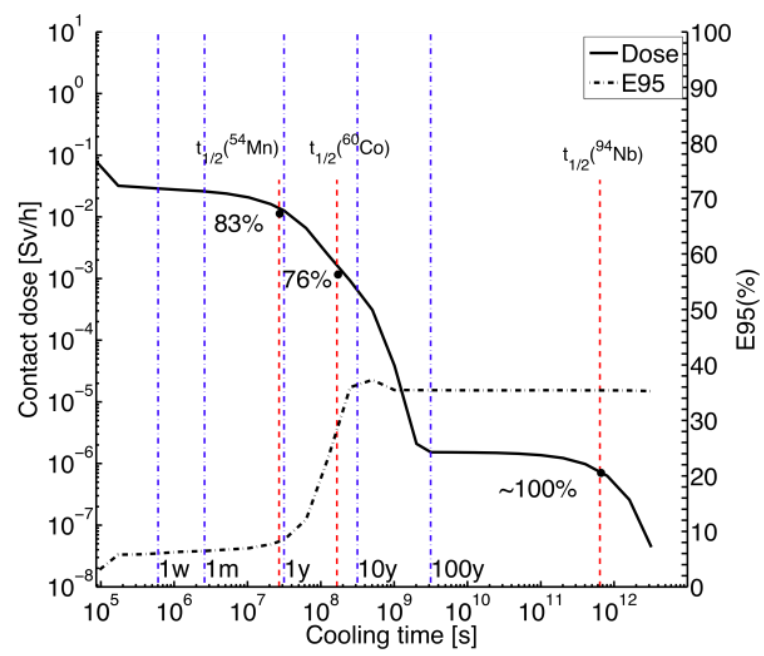

Fig. 5. Contact dose for the T91 steel during the cooling time together with the relative error at $95 \%$ confidence level, E95.

\section{CONCLUSIONS}

All the activated steels have a WDR much lower than the unit, so that they will qualify as Class $\mathrm{C}$ shallow-land burial waste.

Regarding recycling, ${ }^{54} \mathrm{Mn}$ and ${ }^{60} \mathrm{Co}$ are the main contributing isotopes to the contact dose rate when the HoR limit is met. ${ }^{54} \mathrm{Mn}$ is generated from the iron so that its production cannot be reduced in steels. ${ }^{60} \mathrm{Co}$ derives from both Cobalt and Nickel. Lower contents of these elements enable to reach the HoR dose limit at shorter times. The maximum allowable concentrations in a pure iron matrix compatible with reaching the HoR limit at 25 years of cooling time is $0.6 \mathrm{w} \%$ for Nickel and $6 \mathrm{wppm}$ for Cobalt.

Niobium is not as troublesome impurity in steels for the HiPER 4a chamber neutron environment, while its performance in a MFE DEMO scenario is of very high concern. For HiPER 4a, the allowed percentage of Niobium to reach $\mathrm{HoR}$ in 25 years is $0.4 \mathrm{w} \%$. Molybdenum presents no restriction in this irradiation scenario for Contact Dose Rate and for Waste Disposal Rating, while its content is also very limited in the case of MFE environments.

The steels containing $\mathrm{Ni}$ as part of the specified composition are not the most attractive option for the HiPER reactor chamber. This is the case of the austenitic steels. We suggest the T91 ferritic/martensitic steel as the best choice: it has a similar contact dose rate performance (even slightly better) to the EUROFER reduced activation steel with the advantage of being a commercial one.

Regarding waste management assessment of a real heat of T91 with impurities, it is found that the HoR dose limit is reached between 40 and 45 years of cooling time and the WDR is far below one. The clearance is not allowed, since cooling times longer than 500 years will be necessary.

We studied the effect of the presence of Nickel and Cobalt impurity elements in a real heat of T91. If there were no Cobalt in the heat, the cooling time for HoR would be reduced to 20 years, and with the absence of Nickel and Cobalt, to less than 15 years. This means that the impurities effect is not very relevant, since its presence does not require advanced control to allow a reasonable waste management.

The effect of activation cross section uncertainties is not of practical significance to determine eligibility of the considered steels for HIPER 4a reaction chamber in order to ensure an acceptable waste management performance.

\section{ACKNOWLEDGMENTS}

This work has been performed under the auspices of HiPER project. It has been also partially supported by Plan Nacional I + D + I (2008 - 2011) Fusion Nuclear ENE2008-06403-C06-02 MICINN (Spain) and the European Union keep-in-touch Program on IFE.

\section{REFERENCES}

1. J. F. LATKOWSKI, "Occupational Dose Estimate for the National Ignition Facility", UCRL-JC133681 (1999).

2. M. E. SAWAN, "Neutronics Analysis for the Light Ion Beam Reactor LIBRA-LiTE", Fusion Technology, 21, 2133 (1992).

3. R.W. MOIR, R.L. BIERI, X.M. CHEN, T.J. DOLAN, M.A. HOFFMAN, P.A. HOUSE, et al., HYLIFE-II: "A molten-salt inertial energy power plant design”, Fusion Technol., 25 (1994) .

4. S. REYES, J. SANZ, J.F. LATKOWSKI, "Use of clearance indexes to assess waste disposal issues for the HYLIFE-II inertial fusion energy power", Fusion Engineering and Design, 63-64, 257-261 (2002).

5. G. KALININ et al., "Assessment and selection of materials for ITER in-vessel components", Journal of Nuclear Materials, 283-287, 10-19, (2000).

6. H. YAMADA et al., "The neutron irradiation effect on mechanical properties of HIP joint material", Journal of Nuclear Materials, 335, 33-38 (2004).

7. R. L. KLUEH et al., "Impurity effects on reducedactivation ferritic steels developed for fusion 
applications", Journal of Nuclear Materials, 280, 353-359 (2000).

8. R. L. KLUEH et al., "Ferritic/martensitic steels for next-generation reactors", Journal of Nuclear Materials, 371, 37-52 (2007).

9. Final Report of the European Fusion Power Plant Conceptual Study (PPCS), EFDA-RP-RE-5.0, (2005).

10. A. ROBINSON et al. "Evaluation of Biological Dose for ARIES-CS and Comparison with Approximate Contact Dose Approach", UWFDM1375, (2010).

11. R. LINDAU, A. MÖSLANG et al., "Present development status of EUROFER and ODSEUROFER for application in blanket concepts", Fusion Engineering and Design, 75-79, 989-996 (2005).

12. M.C. BILLONE, A.R. RAFFRAY, D.K. SZE, L. ElGUEBALY, the ARIES Team, IFE Structural Materials: ARIES Assessment, University of California, San Diego, UCSD-ENG-101, December (2002).

13. J. SANZ, O. CABELLOS, S. REYES, "Effect of activation cross-section uncertainties in selecting steels for the HYLIFE-II chamber to successful waste management", Fusion Eng. Des., 75-79, 1157-1161 (2005).

14. L. EL-GUEBALY et al "An Integrated Approach to the Back-End of the Fusion Materials Cycle" Fusion Science and Technology, 52, 2, 109-139, (2009).

15. D.B. PELOWITZ, "MCNPX User's Manual", LACP-05-0369 (2005) and extensions.

16. John Perkin's private communication.

17. J. SANZ, O. CABELLOS and N. GARCÍAHERRANZ, "ACAB-2008: Inventory code for nuclear applications”, Nuclear Energy Agency NEA Data Bank., NEA-1839, (December 2008).

18. J-Ch. SUBLET, L. W. PACKER, J. KOPECKY, R. A. FORREST, A. J. KONING and D. A. ROCHMAN, "The European Activation File: EAF2010 neutron-induced cross section libraries", Culham Science Centre, Rept. CCFE-R(10) 05 (March 2010).

19. J. SANZ, R. FALQUINA, A. RODRIGUEZ, O. CABELLOS, S. REYES, J.F. LATKOWSKI, "Monte Carlo uncertainty analysis of pulsed activation in the National Ignition Facility gunite shielding", Fusion Sci. Technol., 43, 473-477 (2003) .

20. R.A. FORREST, J. KOPECKY, J.Ch. SUBLET, EAF-2003 Uncertainty File, EURATOM/UKAEA Fusion Association, Culham Science Center (2003).

21. S. FETTER, et al., "Long term radioactive waste from fusion reactors: part II", Fusion Engineering and Design, 13, 239-246 (1990).
22. L. W. PACKER and J-Ch. SUBLET "The European Activation File: EAF-2010 biological, Clearance and transport libraries", Culham Science Centre, Rept. CCFE-R(10) 04 (March 2010).

23. ICRP publication 60, Annals of the ICRP, Vol. 21, nº1-3 (1990). 